\title{
Qualidade pós-colheita de crisântemos (Dedranthema grandiflora) mantidos em soluções de ácido giberélico
}

\author{
Vase life of chrysanthemum (Dedranthema grandiflora) \\ in gibberellic acid solutions \\ Auri Brackmann ${ }^{1}$ Rogério Antônio Bellé ${ }^{1}$ \\ Sérgio Tonetto de Freitas ${ }^{2}$ Anderson Machado de Mello²
}

\section{RESUMO}

A manutenção da qualidade pós-colheita de flores de corte é extremamente importante para que todo o esforço empregado no aumento da produção seja compensado com a venda do produto. O objetivo deste trabalho foi avaliar o efeito de concentrações de ácido giberélico em solução conservante na manutenção da qualidade pós-colheita de cultivares de crisântemo. O delineamento experimental foi o inteiramente casualizado com cinco repetições. Os tratamentos foram constituídos do acondicionamento das cultivares de crisântemo 'Flippo', 'Recital' e 'Bronze Repim', em soluções com 0, 20, 40, 60, $80,100 \mathrm{mg} \mathrm{L}^{-1}$ de ácido giberélico. A aplicação de ácido giberélico em solução conservante pós-colheita acelerou a senescência das flores e folhas das cultivares de crisântemo avaliadas.

Palavras-chave: conservação, fitorregulador, longevidade.

\section{ABSTRACT}

The maintenance of postharvest quality of cutflowers is extremely important in order to reward the work spent to increase the production with the commercialization of the product. The objective of this work was to evaluate the effect of different gibberellic acid concentrations on quality maintenance of chrysanthemum. The experiment was conducted in a complete random design with five replications. The treatments were composed by the packing of the chrysanthemum cultivars 'Flippo', 'Recital' $e$ 'Bronze Repim', in solutions with 0,20,40,60,80,100mg $\mathrm{L}^{-1}$ of gibberelic acid. The gibberellic acid application in postharvest solution increased the senescence of flowers and leaves of chrysanthemum cultivars evaluated.

Key words: conservation, plant regulator, longevity.

O crisântemo de corte é uma das flores mais comercializadas devido à grande diversidade em cores e formas de inflorescências, assim como pela resposta precisa ao fotoperíodo. Entretanto, apesar dessas características, algumas cultivares de corte apresentam limitado período de conservação em vaso.

O esgotamento de reservas, principalmente dos carboidratos, através do processo respiratório (SKUTNIK et al., 2001), assim como a clorose foliar (MELLO et al., 2001), são fatores que afetam a longevidade pós-colheita de flores de corte. A aplicação exógena de reguladores de crescimento, como giberelinas ou citocininas, interfere na senescência de folhas. Isso pode ser claramente observado em lírio, onde a aplicação do ácido giberélico e benziladenina em folhas isoladas retarda significativamente o amarelecimento e a taxa

${ }^{1}$ Departamento de Fitotecnia, Centro de Ciências Rurais, Universidade Federal de Santa Maria (UFSM), Santa Maria, RS, Brasil. Email: brackman@ccr.ufsm.br. Autor para correspondência.

${ }^{2}$ Programa de Pós-graduação em Agronomia, UFSM, Santa Maria, RS, Brasil. 
respiratória da folhas (FRANCO \& HAN, 1997). A aplicação de ácido giberélico em solução conservante, também pode retardar o amarelecimento de folhas de lírio, porém, não influência a longevidade das flores (MELLO et al., 2001). A aplicação de $20 \mathrm{mg} \mathrm{L}^{-1}$ de ácido giberélico por 24h em rosas aumenta a vida de vaso das flores indiretamente, por meio da diminuição do desenvolvimento de Botrytis cinerea nas pétalas (SHAUL et al., 1995), assim como o uso de ácido giberélico pode prolongar a longevidade de crisântemo, incrementando, assim, sua vida de vaso (D’HOMT et al., 1991). A aplicação foliar de 100mg $\mathrm{L}^{-1}$ de ácido giberélico, além de aumentar a massa das hastes, diâmetro do disco floral e das inflorescências, pode aumentar também a vida de vaso de 12 cultivares de crisântemo (DEHALE et al., 1993). Esse efeito foi observado em crisântemo 'Gompie-chá', no qual a aplicação de 100 $\mathrm{mg} \mathrm{L}^{-1}$, em plantas cultivadas em estufa, prolongou a vida de vaso em 16 dias, em comparação às não tratadas (FREITAS et al., 2001). A indução da absorção de uma solução por meio da exposição das hastes a uma temperatura elevada com baixas doses (10 e 20mg L ${ }^{-1}$ ) de ácido giberélico, também tem mostrado um aumento da durabilidade do crisântemo 'Reagam' em 2,2 dias (LASCHI et al., 1999).

Os resultados dos estudos sobre o efeito do ácido giberélico na taxa de senescência em crisântemo de corte são contraditórios, especialmente em relação à aplicação sobre as plantas em condições de campo. No entanto, em condições mais controladas como em pós-colheita, a utilização de ácido giberélico não está sujeita às interferências climáticas e de crescimento que ocorrem a campo.

O objetivo deste trabalho foi avaliar o efeito de diferentes concentrações de ácido giberélico em solução conservante sobre a qualidade pós-colheita de três cultivares de crisântemo de corte.

As plantas de crisântemo utilizadas, neste experimento, foram produzidas pelo setor de Floricultura, e o experimento foi conduzido no Núcleo de Pesquisa em Pós-Colheita, ambos pertencentes ao Departamento de Fitotecnia da Universidade Federal de Santa Maria, RS.

As flores foram colhidas quando apresentavam aproximadamente $50 \%$ das lígulas (lâmina formada pela soldadura das pétalas das flores externas dos capítulos de certas compostas) expandidas, o que corresponde ao ponto de colheita comercial. Logo após, as hastes foram padronizadas a um comprimento de $75 \mathrm{~cm}$ e com desfolhamento de $15 \mathrm{~cm}$ da base da haste.

O delineamento experimental utilizado foi o inteiramente casualizado com cinco repetições, em que cada repetição foi composta de uma haste com cinco flores. Os tratamentos foram constituídos do acondicionamento das cultivares de crisântemo 'Flippo', 'Recital' e 'Bronze Repim', em soluções com 0, 20, 40, 60, 80, $100 \mathrm{mg} \mathrm{L}^{-1}$ de ácido giberélico. As hastes foram mantidas na temperatura ambiente de 15 a $20^{\circ} \mathrm{C}$. Durante o período de pós-colheita, foram realizadas análises qualitativas com atribuição de notas para as flores e folhas em intervalos de dois dias. Essas análises constituíram-se da atribuição de notas para cada haste, de acordo com o seu estádio de senescência. Para a análise qualitativa das flores, foram levadas em consideração um número de cinco flores por haste, sendo que, para a análise qualitativa das folhas, considerou-se o número total de folhas da haste. As notas utilizadas para as flores foram: nota $0=$ sem defeitos visíveis; nota $1=$ hastes com até três flores apresentando lígulas descoloridas; nota $2=$ hastes com todas as flores apresentando descoloração e até duas flores com inicio de murchamento; nota $3=$ haste com todas as flores apresentando lígulas murchas; nota $4=$ hastes com todas as flores apresentando lígulas murchas e início de secamento; nota 5 =hastes com todas as flores apresentando lígulas secas. As notas utilizadas para as folhas foram: nota $0=$ sem defeito visível na folha; nota $1=$ folhas em início de murchamento (folhas pendentes); nota 2 =folhas com murchamento e início de amarelecimento; nota $3=$ folhas apresentando bordas secas; nota $4=$ folhas com até $90 \%$ de secamento do limbo folhar; nota $5=$ folhas completamente secas. $\mathrm{O}$ tempo de vida de vaso para a flor e folha foi determinado quando estes órgãos apresentaram nota igual ou superior a 3 , ou seja, sem qualidade para comercialização. As análises estatísticas realizadas para cada cultivar, isoladamente, foram realizadas no momento em que o pior tratamento apresentou nota igual ou superior a 3 para a flor em todas as suas repetições. Este parâmetro foi definido devido à flor ser o principal órgão responsável pela estética das hastes. Desta forma, as cultivares Recital, Bronze Repim e Flippo, foram avaliadas estatisticamente aos 17, 23 e 25 dias após a colheita, respectivamente. Os dados obtidos foram submetidos a análise de variância e as médias comparadas pelo teste de Duncan a 5\% de probabilidade de erro. 
A solução contendo ácido giberélico reduziu significativamente a vida das flores. Observou-se ainda que as cultivares sem o uso de solução com ácido giberélico, tiveram uma longa vida de vaso, sendo que as flores só feneceram após um período de 27 dias (Tabela 1). A análise da variância mostrou um efeito significativo, para todas as cultivares, com relação às doses de ácido giberélico. O percurso da taxa de senescência da cultivar Recital após 17 dias (Figura 1A) apresentou comportamento do tipo linear crescente, porém, com um efeito acentuado de dose, em que as hastes sem ácido giberélico permaneceram praticamente intactas. A senescência das folhas pôde ser representada por uma curva de resposta quadrática, na qual se observa que as hastes sem ácido giberélico apresentavam-se intactas aos 17 dias, e uma evolução muito rápida da senescência, pois com dose igual ou superior a $60 \mathrm{mg} \mathrm{L}^{-1}$ todas as folhas já haviam perecido.

Na cultivar Bronze Repim, aos 23 dias de vida de vaso (Figura 1B), observou-se que a senescência teve um comportamento semelhante tanto para flor como para folha, pois envelheceram praticamente num mesmo ritmo, à medida que as doses foram aumentadas. Esse ritmo pode ser representado por curvas de resposta cúbica, com a perda da vida de vaso somente para a dose de $100 \mathrm{mg} \mathrm{L}^{-1}$.

Ao avaliar os resultados obtidos para a cultivar Flippo aos 25 dias de vida de vaso (Figura 1C), verificou-se que a evolução da senescência da flor pode ser representada por uma equação linear crescente, significando que a mesma evoluiu proporcionalmente com o aumento das doses de ácido giberélico. Somente as flores nas soluções com 80 e $100 \mathrm{mg} \mathrm{L}^{-1}$ haviam encerrado sua vida de vaso até essa data. A senescência de folhas, entretanto, evoluiu de forma diferente e pode ser representada por uma curva de resposta cúbica, porém, com baixo coeficiente de determinação $\left(\mathrm{r}^{2}=0,42\right)$.

Ficou evidente que o ácido giberélico promoveu aceleração da senescência, tanto de flores como de folhas, apesar dos resultados contraditórios, observados na maioria da bibliografia consultada. No entanto, alguns autores afirmam que a ação das giberelinas pode variar de acordo com a espécie (KING, 1997; PAULIN, 1997; LASCHI et al., 1999), o local de aplicação (KING, 1997) e o tipo de giberelina usada (HAN, 1997), o que pode explicar o
Tabela 1 - Tempo de vida de vaso de inflorescências e folhas de três cultivares de crisântemo de corte em função do uso de solução com ácido giberélico $\left(\mathrm{AG}_{3}\right)$. Santa Maria, RS, 2002.

\begin{tabular}{lcccc}
\hline \multirow{2}{*}{ Cultivar } & \multirow{2}{*}{ Órgão } & $\begin{array}{c}\mathrm{CV} \\
\text { (\%) }\end{array}$ & & \multicolumn{2}{c}{ Vida de vaso (dias) } \\
\cline { 4 - 5 } Flippo & Flor & 2,74 & $29,0 \mathrm{a} *$ & $20,3 \mathrm{~b}$ \\
& Folha & 2,03 & $29,0 \mathrm{a}$ & $27,8 \mathrm{~b}$ \\
\multirow{2}{*}{ Recital } & Flor & 2,42 & $27,0 \mathrm{a}$ & $20,6 \mathrm{~b}$ \\
& Folha & 4,30 & $31,0 \mathrm{a}$ & $10,6 \mathrm{~b}$ \\
Bronze & Flor & 2,42 & $27,0 \mathrm{a}$ & $24,6 \mathrm{~b}$ \\
Repim & Folha & 4,30 & $31,0 \mathrm{a}$ & $28,6 \mathrm{~b}$ \\
\hline
\end{tabular}

*Médias não seguidas pela mesma letra na horizontal diferem estatisticamente entre si pelo teste de Duncan em nível de 5\% de probabilidade de erro.

** Valores obtidos por meio das médias das doses de ácido giberélico.

aumento da longevidade pós-colheita de crisântemos tratados com giberelina em précolheita (FREITAS et al., 2001).

A ação do ácido giberélico, quando aplicado em pós-colheita, pode acelerar o metabolismo e não reduzí-lo (FRANCO \& HAN, 1997). As deficiências de nutrição veiculadas pela solução conservante e intensidade luminosa, são capazes de suprimir os assimilados, podendo assim causar a aceleração dos processos de senescência das hastes florais com o aumento das doses de ácido giberélico.

Outros fatores que podem ainda estar relacionados à eficiência do ácido giberélico, são a forma e a época de aplicação (DEHALE et al., 1993; FREITAS et al., 2001; LASCHI et al., 1999). Portanto, a avaliação da senescência de crisântemo sob efeito do ácido giberélico merece maior atenção, especialmente outras investigações comparativas com aplicações em campo e pós-colheita para diversas cultivares, a fim de definir melhor um método de conservação e identificação de diferenças varietais com o uso de giberelinas. O uso de 20, 40, 60, 80 e 100 $\mathrm{mg} \mathrm{L}^{-}$ ${ }^{1}$ de ácido giberélico em soluções conservantes acelerou a senescência de flores e folhas de crisântemo das cultivares Flippo, Recital e Bronze Repim, diminuindo a vida de vaso.

\section{AGRADECIMENTOS}

Freitas e Mello, bolsistas do Conselho Nacional de Desenvolvimento Científico e Tecnológico (CNPq). 

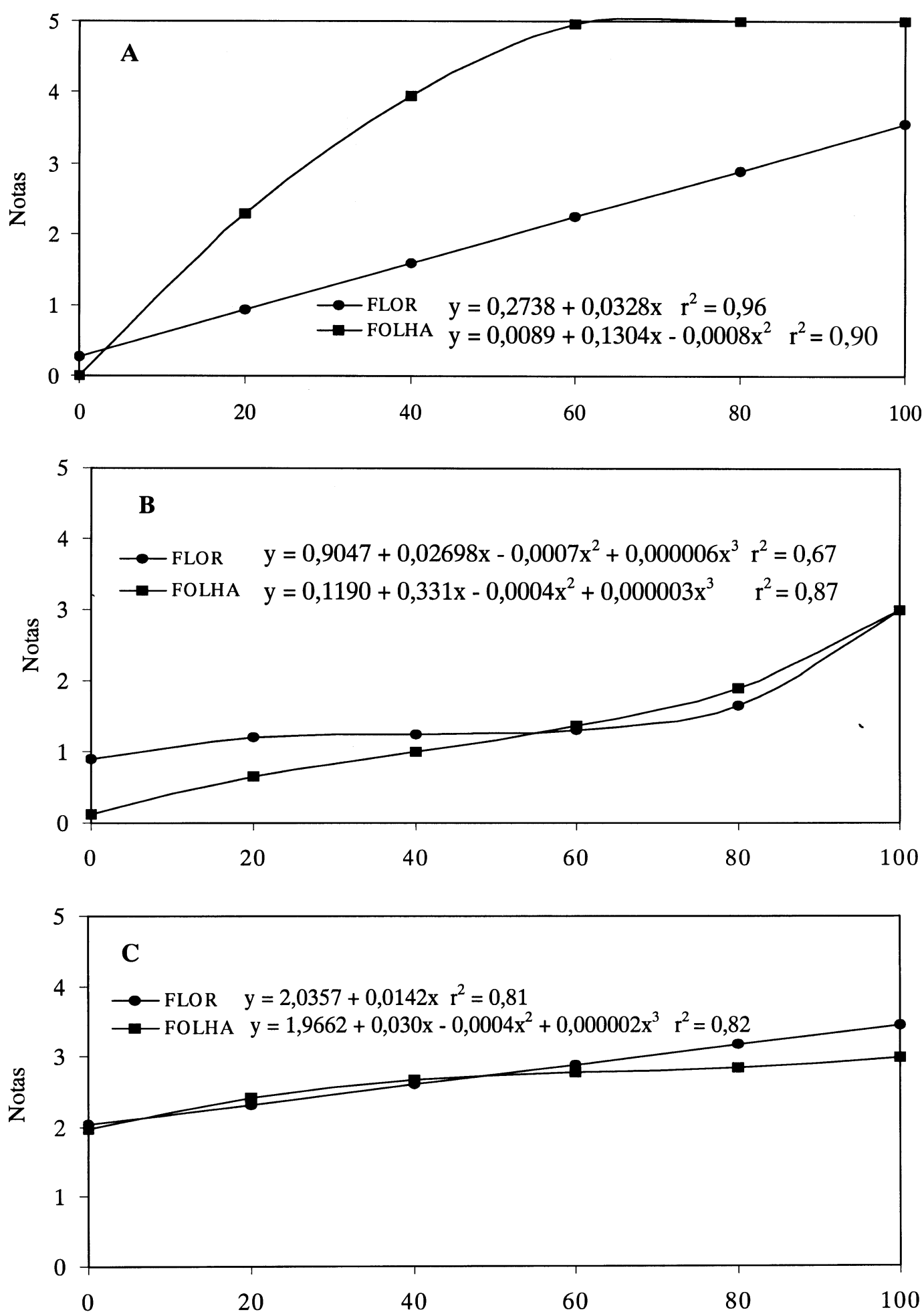

Doses de ácido giberélico $\left(\mathrm{mg} \mathrm{L}^{-1}\right)$

Figura 1 - Senescência de flores e folhas de crisântemo cvs. Recital (A), Bronze Repim (B) e Flippo (C) aos 17, 23 e 25 dias de vida de vaso, respectivamente, em função da dose de ácido giberélico em solução.

Ciência Rural, v.35, n.6, nov-dez, 2005. 


\section{REFERÊNCIAS}

DEHALE, M.H. et al. Lufluevre of foliar aplication of $\mathrm{GA}_{3}$ on quality of chrysanthemum. Journal of Soils and Crops, v.2, n.6, p.135-137, 1993

D'HONT, K. et al. The effects of different growth regulators and chemical treatments used during post harvest for preserving quality of chrysanthemums. Acta Horticultural, v.298, n.1, p.211-214, 1991.

FRANCO, R.E.; HAN, S.S. Respiratory changes associated with growth-regulator delayed leaf yellowing in Easter lily. Journal American Society Horticultural Science, Alexandria, v.122, n.2, p.117121,1997

FREITAS, S.T. et al. Aplicação de ácido giberélico a campo na vida de vaso de crisântemo 'Gompie-chá'. In: MOSTRA DE INICIAÇÃO CIENTÍFICA, 4., 2001, Cachoeira do Sul. Anais... Cachoeira do Sul: ULBRA, 2001. V.4, p.184.

HAN, S. Application of growth regulators to delay the development of foliar chlorosis on Easter lilies. Journal American Society Horticultural Science, v.122, n.3, p.254-258, 1997.
KING, R.W. Gibberellins in relation to growth and flowering in Pharbiitis nil Chois. Camberra. Plant Phisiology, v.84, n.1, p.1126-1131, 1997.

LASCHI, D. et al. Efeito de ácido giberélico, $\mathrm{GA}_{3}$ e $\mathrm{GA}_{4}+$ $\mathrm{GA}_{7}$, em pós-colheita de crisântemo e solidago. Revista Brasileira de Horticultura e Ornamentais, Campinas, v.5, n.2, p.143-149, 1999.

MELLO, A.M. et al. Aplicação de ácido giberélico em solução conservante na prevenção pós-colheita do amarelecimento de folhas de Lilium longiflorum cv. Snow Queen. In: MOSTRA DE INICIAÇÃO CIENTÍfICA, 4., 2001, Cachoeira do Sul. Anais... Cachoeira do Sul: ULBRA, 2001. V.4, p.183.

PAULIN, A. Poscosecha de las flores cortadas bases fisiológicas. Bogotá: Hortitécnica, 1997. 100p.

SHAUL, O. et al. Suppression of Botrytis blight in cut rose flowers with gibberellic acid: effect of concentrations and mode of application. Postharvest Biology and Technology, v.6, n.6, p.321-330, 1995.

SKUTNIK, E. et al. Effect of growth regulators on postharvest characteristics of Zantedeschia aethiopica. Postharvest Biology and Technology, v.21, n.2, p.241-246, 2001. 